UCRL-ID- 149951

\title{
Report on Radiation Damage Effects in a Titanium Target under Photon Irradiation
}

\author{
M.-J. Caturla, S. Roesler, V. K. Bharadwaj, \\ D. C. Shultz, J. C. Sheppard, J. Marian, B. D. \\ Wirth, W. Stein and A. Sunwoo
}

\section{August 30, 2002}

U.S. Department of Energy

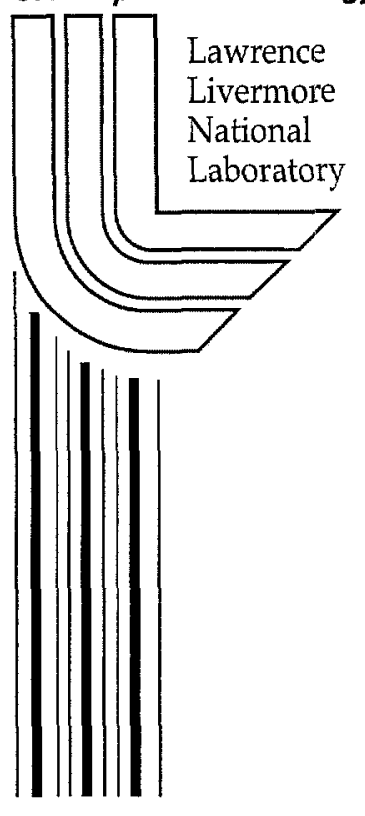





\section{DISCLAIMER}

This document was prepared as an account of work sponsored by an agency of the United States Government. Neither the United States Government nor the University of California nor any of their employees, makes any warranty, express or implied, or assumes any legal liability or responsibility for the accuracy, completeness, or usefulness of any information, apparatus, product, or process disclosed, or represents that its use would not infringe privately owned rights. Reference herein to any specific commercial product, process, or service by trade name, trademark, manufacturer, or otherwise, does not necessarily constitute or imply its endorsement, recommendation, or favoring by the United States Government or the University of California. The views and opinions of authors expressed herein do not necessarily state or reflect those of the United States Government or the University of California, and shall not be used for advertising or product endorsement purposes.

This is a preprint of a paper intended for publication in a journal or proceedings. Since changes may be made before publication, this preprint is made available with the understanding that it will not be cited or reproduced without the permission of the author.

This report has been reproduced directly from the best available copy.

Available to DOE and DOE contractors from the Office of Scientific and Technical Information

P.O. Box 62, Oak Ridge, TN 37831

Prices available from (423) 576-8401

http://apollo.osti.gov/bridge/

Available to the public from the National Technical Information Service

U.S. Department of Commerce 5285 Port Royal Rd., Springfield, VA 22161 http://www.ntis.gov/

OR

Lawrence Livermore National Laboratory Technical Information Department's Digital Library http://www.linl.gov/tid/Library.html 

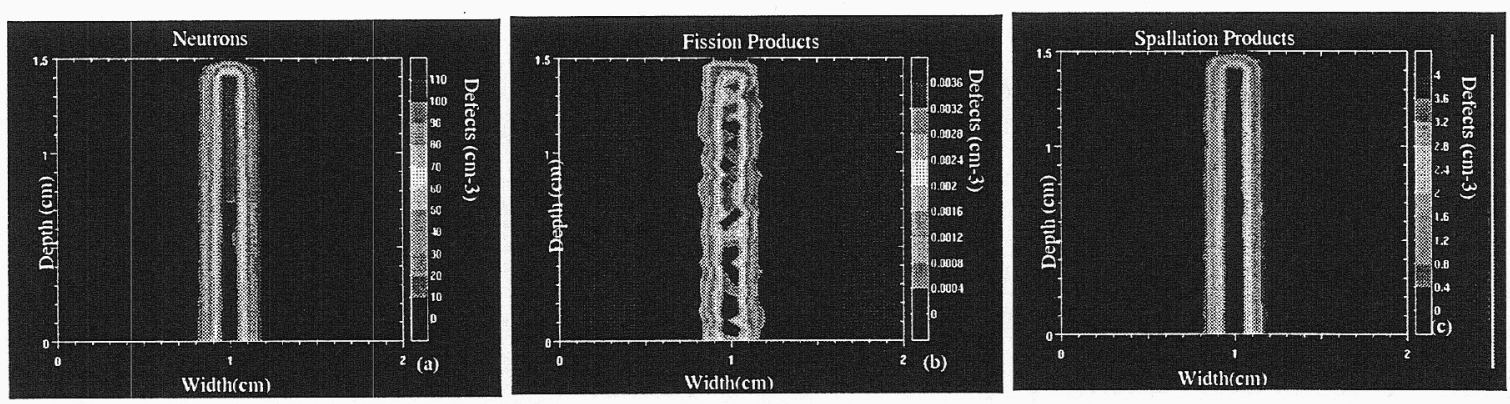

Figure 2: Defects per $\mathrm{cm}^{3}$ due to (a) neutrons (b) fission products and (c) spallation products.

For comparison we show the total number of defects for the Ti target under photon irradiation together with the results of the NLC W-Re target under electron irradiation in Figures 3(a) and (b) respectively.
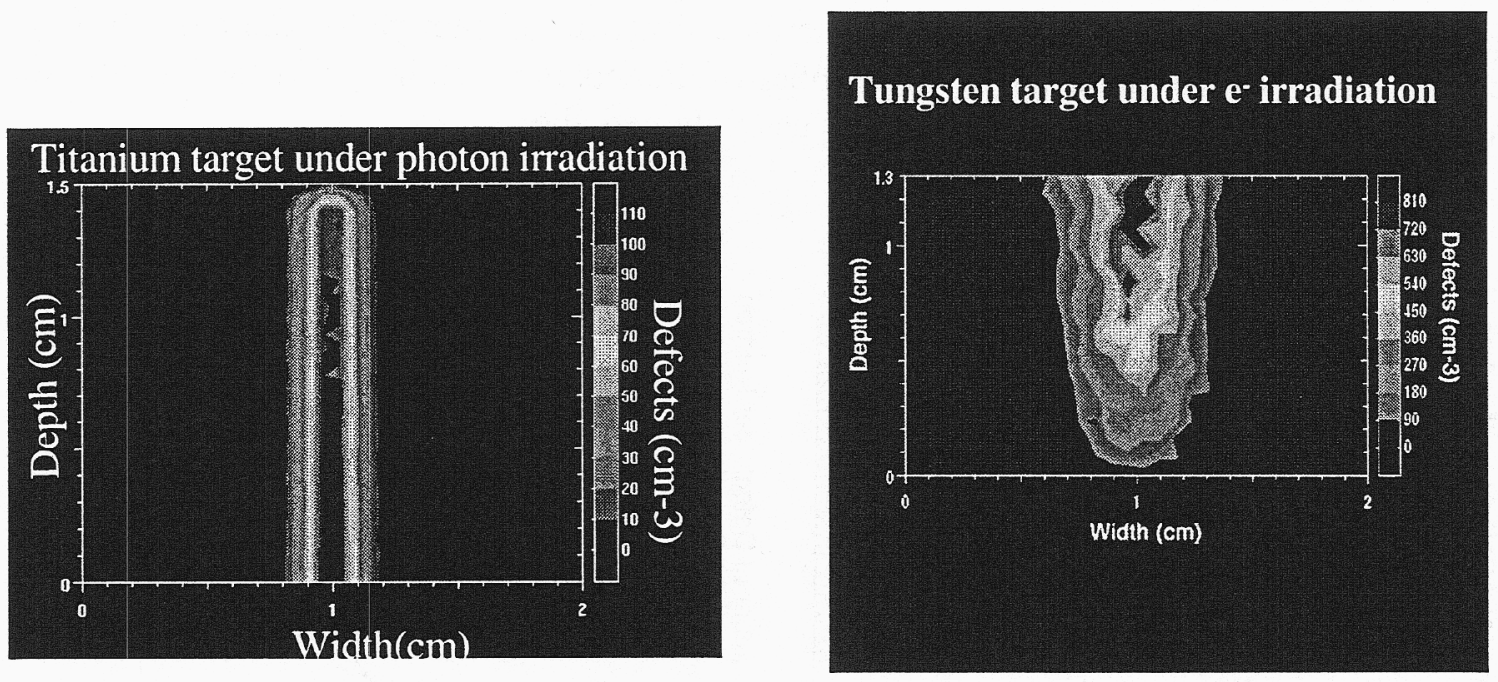

Figure 3: Defects per $\mathrm{cm}^{3}$ produced (a) per photon in a Titanium target and (b) per electron in a W-Re target.

Several significant differences are observed between the irradiation with electrons and with photons. In the case of electrons most of the damage is produced at the back surface of the target, due to cascade effects. In the case of photons the damage is higher in the front surface and there is no much dispersion. The maximum number of defects per incident electron is larger than the maximum number of defects per photon, $(\sim 8 \mathrm{x}$ higher defects in the electron irradiation). 


\section{Report on Radiation Damage effects in aTitanium Target Under Photon Irradiation}

\section{M.J. Caturla, 08/30/02}

Following the same approach as with the W-Re targets [1], we have calculated the damage induced by photon irradiation $(22.1 \mathrm{MeV}$ average energy) in titanium targets. Stefan Roesler calculated, using FLUKA [2] the spallation products, neutrons and fission products from the interaction of the photons with the titanium target.

Using these initial values of energies and positions, we calculated the number of defects produced per incoming photon. It should be noted that the threshold displacement energy for defect production of Titanium as measured experimentally is between 21 and $30 \mathrm{eV}$ [3]. We used a value of $25 \mathrm{eV}$. This is a much lower value than for the case of W-alloys $(90 \mathrm{eV})$ which implies a larger defect production for the same deposited energy in the case of Titanium.

The number of defects for different neutron energies was calculated using SPECTER [4] Figure 1(a) shows the number of defects as a function of energy for the case of Ti as compared to W, in Figure 1(b). The number of defects is much larger in the Ti case due to the low threshold displacement energy as explained above.
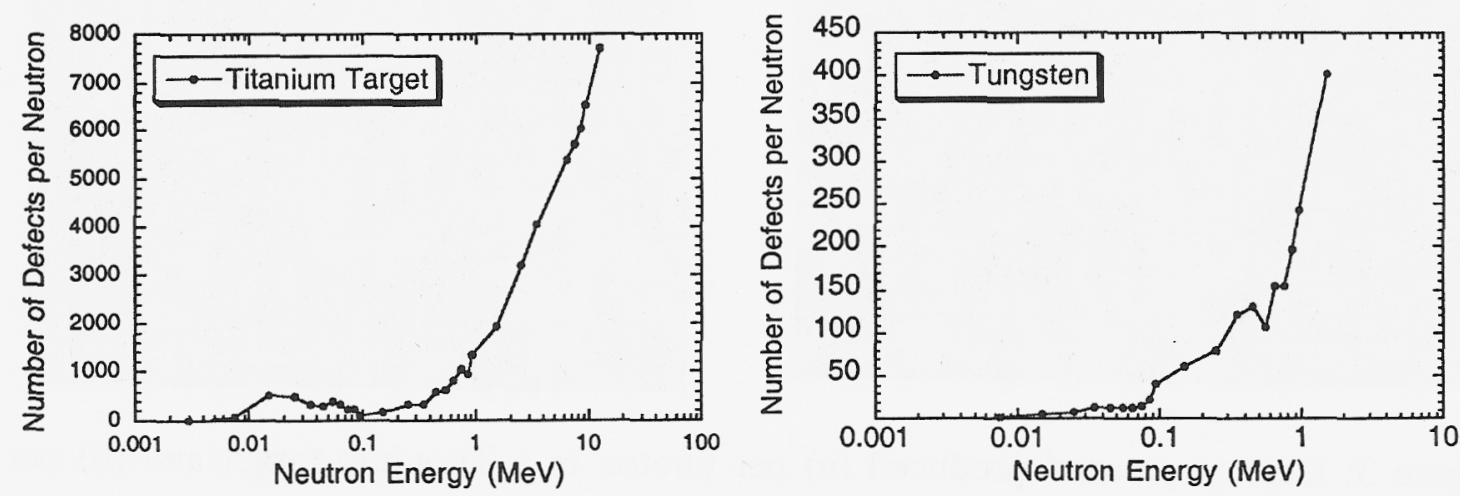

Figure 1. Defects per Neutron as a function of neutron energy as obtained by SPECTER for (a) Titanium and (b) Tungsten.

The contour plots of the number of defects for the width $(0.75 \mathrm{~mm}$ spot radius) and depth $(1.5 \mathrm{~cm}$ ) of the target are presented in Figure 2, for the case of (a) the defects produced by neutrons, (b) defects produced by spallation products and (c) defects produced by fission products. The number of spallation and fission products in this case is very small and only the neutrons produce a significant amount of defects. This was also the case in electron irradiation and $\mathrm{W}$ targets but it is even more pronounced in this case. 
We have calculated the total damage produced in the titanium target for 1 year operation, considering that 1 spot receives 1 pulse per second with 190 bunches per pulse and a $1.1 \times 10^{12}$ photons per bunch. This results in a total of $6.59 \times 10^{21}$ photons/year. As a comparison, a W-Re target spot receives $1.22 \times 10^{20}$ electrons in 3 years for the NLC configuration. The dose in a year in the Ti target is $54 \mathrm{x}$ higher than the dose in the W-Re target in 3 years. From the analysis above, the damage per photon is only 1 order of magnitude smaller than the damage per electron. This lower damage does not compensate for the higher dose that this target will receive, resulting in a much higher damage level in the Ti targets. Figure 4(a) shows the damage for the Ti target in a year as compared to the previously calculated damage in the W-Re target for the NLC configuration in 3 years (Figure 4(b)). The damage is calculated in DPA (displacements per atom). The DPA is calculated as:

[ number of defects per photon (defects $/ \mathrm{cm}^{3}$ ) $\mathrm{x}$ dose (number of photons) ] / density $\left(\right.$ atoms $/ \mathrm{cm}^{3}$ ).

The density used for Ti in these calculations is $5.6 \times 10^{22}$ atoms $/ \mathrm{cm}^{3}$.
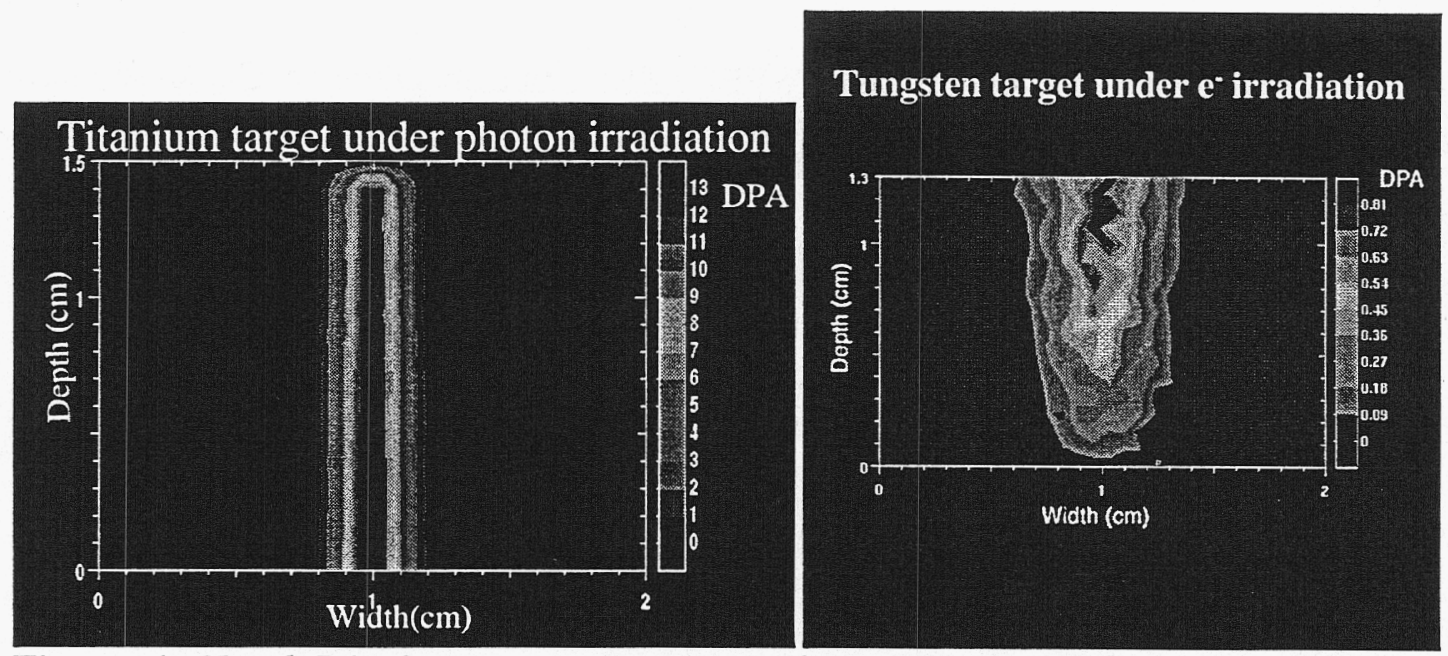

Figure 4: Total Displacements Per Atom for a (a) Titanium target under photon irradiation for 1 year and a (b) W-Re target under e-irradiation for 3 years.

The maximum DPA expected in the Ti target is on the order of 13 dpa while the W target maximum values obtained were below $1 \mathrm{dpa}$. Values near 1 dpa have been shown to result in material damage and brittleness in SLAC W-26\%Re material targets .

This work was performed under the auspices of the U. S. Department of Energy by the University of California, Lawrence Livermore National Laboratory under Contract No. W-7405-Eng-48. 


\section{References:}

[1] M.-J. Caturla, S. Roesler, V. K. Bharadwaj, D. C. Shultz, J. C. Sheppard, J. Marian, B. D. Wirth, W. Stein and A. Sunwoo, "Radiation Damage Induced by GeV Electrons in W-Re Targets for Next Generation Linear Colliders" UCRL-JC-148049

[2] A.Fasso', A.Ferrari, P.R.Sala, "Electron-photon transport in FLUKA: status", Proceedings of the MonteCarlo 2000 Conference, Lisbon, October 23-26 2000, A.Kling, F.Barao, M.Nakagawa, L.Tavora, P.Vaz - eds., Springer-Verlag Berlin, p.159-164 (2001). A.Fasso', A.Ferrari, J.Ranft, P.R.Sala, "FLUKA: Status and Prospective for Hadronic Applications", Proceedings of the MonteCarlo 2000 Conference, Lisbon, October 23-26 2000, A.Kling, F.Barao, M.Nakagawa, L.Tavora, P.Vaz - eds. , SpringerVerlag Berlin, p.955-960 (2001).

[3] G. Sattonnay, F. Rullier-Albenque, O. Dimitrov, Journal of Nuclear Materials 275 (1999) 63-73

[4] L. R. Greenwood, R. K. Smither, "SPECTER: Neutron Damage Calculationsfor materials Irradiations", ANL/FPP/TM-197, Argonne, IL, January 1985 